bewarb, wurde ich ausdrücklich nur deshalb nicht zugelassen, weil ich hatte durchblicken lassen, dass ich verlobt sei und gelegentlich zu heiraten gedenke. "Dann können wir Sie leider nicht anstellen», war die Antwort, "ein Assistenzarzt muss bei uns im Spital in einem Zimmer wohnen und Tag und Nacht für den Spitaldienst bereit sein!» Es wurde mir versichert, es sei dies auch bei anderen Bezirksspitälern so. An einer Universitätsklinik wollte ich mich vorerst nicht anmelden, bevor ich nicht an einem Bezirksspital nochmals in allgemeiner Medizin gearbeitet hatte, um mir wirklich über meine beruflichen Pläne klar zu werden. Ich nahm zwischenzeitlich eine Assistentenstelle an einer Privatklinik an. Es war mir möglich zu heiraten, wobei allerdings mein ganzer Lohn bis auf den letzten Rappen für ein Dachzimmer für mich und meine Frau und Kost aufging. Was sie an einem anderen Ort erarbeitete, verschaffte uns das nötige "Kleingeld», auch für meine Bücher, um mich fortzubilden. Es kam dann doch dazu, dass meine alten Pläne, Psychiater zu werden, wieder aufkamen. An psychiatrischen Kliniken waren auch Stellen frei, an denen niemand etwas dagegen hatte, wenn ich sie verheiratet antrat und erst noch zu einem Lohn, der es meiner Frau gestattete, nur noch halbtags zu arbeiten. Allerdings hatte ich - es war im Kloster Rheinau - jeden zweiten Tag Präsenzdienst an der Klinik, an der ich auch zu übernachten hätte, durchaus ohne dass sich dies in der Höhe meines Lohnes niedergeschlagen hätte! Tempora mutantur!

\section{Buchstaben statt Pillen}

\author{
H. Sprenger
}

Schreiben oder auch Lesen als Therapie, als Mittel zu vertiefter Selbsterkenntnis, sogar als Eigentherapie ist kein modernes Phänomen, sondern hat eine lange Tradition. Bei den Griechen wurde Apollo, der Vater des Asklepios, als Gott der Heilkunst und der Dichtkunst verehrt. Die antiken Bibliotheken in Alexandria und in Theben galten als "heilende Orte» und als "Medizin für die Seele». Bekannt ist auch die Trostliteratur, z.B. die Trostbriefe des Cicero, die Schriften von Ambrosius und Augustinus sowie die Trostbücher des Thomas von Kempen, die über Jahrhunderte zur Linderung von Leid, körperlichen Schmerzen oder seelischer Krankheit verwendet wurden. In amerikanischen Spitälern begann man bereits im 19. Jahrhundert, ausgewählte Literatur zur Behandlung von psychisch Kranken einzusetzen. Auch im deutschsprachigen Raum fasst die Poesie- und Bibliotherapie langsam Fuss. Immer häufiger wird die Heilkraft der gestalteten Sprache in verschiedenen Arbeitsfeldern und Berufen, in Psychotherapie, Rehabilitation, in der Seelsorge, in der Arbeit mit alten und behinderten Menschen und in der Begleitung Sterbender und Schwerkranker genutzt.

Korrespondenz: Heidi Sprenger Im Lee 3 CH-8712 Stäfa

\section{Wie wirkt Poesie- und Bibliotherapie?}

Die therapeutische Arbeit mit Literatur (Romane, Märchen, Kurzgeschichten, Poesie) und mit selbstgeschriebenen Texten eröffnet Zugänge zu den Quellen eigener Lebens- und Wertvorstellungen, ermöglicht Einblicke in bisher unbeachtete Zusammenhänge oder Konflikte und verschafft gleichzeitig Distanz, indem der Patient den Text lesen, mitteilen, auf sich wirken lassen kann. Aus dem so entstandenen neuen Blickwinkel kann er klarer sehen, tiefer verstehen, erklären und möglicherweise auch etwas verändern. Ausserdem werden die Selbstheilungskräfte des Patienten angeregt. Poesie- und Bibliotherapie hilft, Sprachlosigkeit zu überwinden, gibt Menschen ihre Kreativität zurück, stärkt ihre Selbständigkeit.

Das «Fritz Perls Institut» (FPI) in Hückeswagen (D) führt seit 1987 Weiterbildungsseminare in Form von Kompakt-Curricula durch (4 Seminare von je 4 Tagen im Laufe eines Jahres), in denen ÄrztInnen, PsychotherapeutInnen, BibliothekarInnen, SchriftstellerInnen und Angehörige pflegerischer und sozialer Berufe sich Kenntnisse über die Methoden und Techniken der Integrativen Poesie- und Bibliotherapie aneignen können. Seit 1997 werden diese Seminare auch in der Schweiz angeboten.

Das nächste Curriculum beginnt am 30. November dieses Jahres und wird von Anja Burr (Germanistin und Gestaltseelsorgerin FPI) und Heidi Sprenger (Integrative Kunst- und Kreativitätstherapeutin FPI) geleitet.

Anmeldungen sind direkt ans FPI, Wefelsen 5, D-42499 Hückeswagen, Tel. +49 21928580 zu richten. Weitere Auskünfte über Kosten, genaue Termine usw. gibt Heidi Sprenger, Tel. 019266000. 